TECNOLOGIA PÓS-COLHEITA

\title{
INDUÇÃO DO AMADURECIMENTO DE MANGAS CV. TOMMY ATKINS E CV. UBÁ PELA APLICAÇÃO DE ETHEPHON PÓS-COLHEITA ( $\left.{ }^{1}\right)$
}

\author{
VAMBERTO BARBOSA BRAZ $\left({ }^{*}\right)$; ENDSON SANTANA NUNES $\left({ }^{3}\right)$; GERIVAL VIEIRA $\left({ }^{3}\right)$; \\ JOSÉ IVO RIBEIRO JÚNIOR $\left({ }^{4}\right)$; LEOPOLDO ARAÚJO BERTINI $\left({ }^{5}\right)$; \\ FLÁVIO ALENCAR D’ ARAÚJO COUTO $\left({ }^{3}\right)$
}

\begin{abstract}
RESUMO
Buscou-se, neste trabalho, induzir o amadurecimento de mangas (Mangifera indica L.) cv. Ubá e cv. Tommy Atkins com a aplicação pós-colheita de ethephon e avaliar seu efeito sobre características físicas e químicas consideradas determinantes na conservação e qualidade dos frutos. Metade da amostra de frutos foi imersa em água, e metade, em solução de ethephon a $1.000 \mathrm{mg} . \mathrm{L}^{-1}$. Para cada variedade, foi desenvolvido um experimento no delineamento inteiramente casualizado, em esquema de parcelas subdivididas, com três repetições, sendo na parcela os tratamentos com e sem aplicação de ethephon e nas subparcelas, as cinco épocas de avaliação após a colheita (no dia da colheita e 3, 6, 9 e 12 dias após a colheita). Com base nas análises de firmeza da polpa, perda de massa fresca, cor da casca e da polpa, conteúdo de sólidos solúveis (SS) e acidez total titulável (ATT), índice de degradação de amido e relação SS/ATT, a aplicação pós-colheita de ethephon foi eficiente em acelerar o amadurecimento das mangas cv. Tommy Atkins e cv. Ubá e contribuir para a obtenção de características desejáveis em um menor período de armazenamento sob condição ambiente, exceto em relação à firmeza da polpa. Neste caso, considerando a importância dessa característica na avaliação da qualidade dos frutos comercializados in natura, a aplicação de ethephon foi prejudicial, principalmente para mangas da variedade Ubá, pois reduziu a vida útil dos frutos devido ao total amolecimento da polpa verificado pelo menos três dias após a colheita.
\end{abstract}

Palavras-chave: Mangifera indica L., amadurecimento, etileno, manga.

$\left({ }^{1}\right)$ Recebido para publicação em 30 de março de 2006 e aceito em 9 de agosto de 2007.

$\left({ }^{2}\right)$ Superintendência Federal de Agricultura, Pecuária e Abastecimento no Estado do Piauí, 64001-340 Teresina (PI).E-mail: vamberto.braz@agricultura.gov.br $\left(^{*}\right)$ Autor correspondente.

$\left({ }^{3}\right)$ Departamento de Fitotecnia, Universidade Federal de Viçosa, 36571-000 Viçosa (MG), Brasil.

$\left({ }^{4}\right)$ Departamento de Informática, Universidade Federal de Viçosa, 36571-000 Viçosa (MG), Brasil.

$\left({ }^{5}\right)$ Superintendência Federal de Agricultura, Pecuária e Abastecimento no Estado de Ceará, 60410-410 Fortaleza (CE), Brasil. 


\title{
ABSTRACT \\ INITIATION OF RIPENING OF TOMMY ATKINS AND UBÁ MANGOES WITH POSTHARVEST APPLICATION OF ETHEPHON
}

\begin{abstract}
This work was developed aiming to induce ripening of mangoes (Mangifera indica L.) cv Ubá e cV Tommy Atkins after postharvest application of ethephon and to evaluate its effect on physical and chemical attributes that characterize preservation and quality of fruits. Half of fruits sample was submersed in water, while other half of fruits was submersed in water solutions containing $1,000 \mathrm{mg} . \mathrm{L}^{-1}$ of ethephon. A split plot design with three replications was used. The main plot was composed of treatments with application and no application of ethephon and the by-plots were composed of five periods of evaluation (in the day of harvest and 3, 6, 9, and 12 days after harvest). Based on analyses of pulp firmness, weight loss, contents of soluble solids (SS) and total titratable acidity (TTA), starch degradation index and ratio SS/TTA, postharvest application of ethephon was efficient to accelerate the ripening of mangoes cv Tommy Atkins e cv Ubá and to contribute for obtaining desirable characteristics in a smaller storage period at environmental conditions, except for regarding pulp firmness. In this case, having in mind the importance of this characteristic to determine quality in fresh fruits, the application of ethephon was damaging, mainly for mangoes cv Ubá, reducing shelf life of fruits because of total softening of pulp verified at least three days after harvest.
\end{abstract}

Key words: Mangifera indica L., ripening, ethylene, mango.

\section{INTRODUÇÃO}

O Brasil é o sétimo produtor mundial de manga, com uma produção superior a $850 \mathrm{mil}$ toneladas anuais, ficando atrás apenas do México e de países asiáticos, como a Índia, maior produtor mundial (FAO, 2004). Dentre as variedades exploradas, a mangueira cv. Tommy Atkins concentra em torno de $90 \%$ da área plantada de manga no país (Almeida et al., 2001), justificada, muitas vezes, por sua rusticidade, coloração atraente, boa conservação póscolheita e relativo equilíbrio na produção entre anos consecutivos.

No Estado de Minas Gerais, a cv. Ubá representa outra variedade bastante difundida e de grande importância comercial, notadamente na região da Zona da Mata, destacando-se pela excelente aceitação no mercado consumidor local e pela larga utilização como matéria-prima pelas indústrias de processamento da região. BERNIZ (1984), caracterizando algumas variedades de mangueira em relação ao seu potencial para processamento industrial, indica a manga cv. Ubá como a melhor para a elaboração de néctar, devido ao seu maior rendimento em polpa, melhor consistência, elevado conteúdo de açúcares e acidez total e, principalmente, pela preferência na avaliação sensorial.

A mangueira (Mangifera indica L.) é um fruto climatérico que quando exposto à aplicação exógena de etileno sofre um incremento na atividade respiratória e na biossíntese desse hormônio (MedLICotT et al., 1987). Em condições normais, esse hidrocarboneto gasoso liga-se a moléculas receptoras, provavelmente proteínas de membrana, de onde surgem respostas associadas ao amadurecimento, podendo afetar a qualidade de produtos hortícolas, como cor, textura e aroma.

As mudanças físicas e químicas que ocorrem nos frutos durante o amadurecimento podem afetar sua qualidade e conservação. No entanto, um único padrão de amadurecimento não pode ser aplicado a todas as espécies, devido ao envolvimento de diferentes rotas na produção de pigmentos, componentes de sabor e aroma e à variação de mecanismos de acúmulo e metabolismo no processo de amolecimento (Abeles et al., 1997). Durante o processo de amadurecimento da manga, pode-se verificar várias alterações, como na firmeza da polpa, nos teores de açúcares, na coloração da casca e da polpa, na composição e teor de ácidos orgânicos e na perda de massa (FucHs et al., 1975). É importante o conhecimento dessas alterações para produtos específicos, visando ao estabelecimento de tecnologias adequadas de manuseio e tratamentos pós-colheita.

Para Chitarra e Chitarra (1990), o amadurecimento corresponde ao processo compreendido entre o estádio de maturação fisiológica, posterior a uma fase incompleta e caracterizada pelo crescimento pleno do fruto, e o fim da maturação. A partir daí, inicia-se o processo de senescência do fruto, cujos processos bioquímicos desta fase substituem as trocas químicas do amadurecimento. Em linhas gerais, o estádio de maturação adequado da manga no momento da colheita deve ser tal que permita a evolução do processo de amadurecimento até que se desenvolvam todas as características correspondentes à variedade cultivada. Entre os indicadores que caracterizam um fruto maduro, podem-se citar: mudança de cor da polpa de branca 
para amarela e, no caso da cor da casca, de verde para a cor característica da variedade quando em um estádio de maturação mais avançado, teor de sólidos solúveis entre 7 e $8^{\circ}$ Brix e firmeza da polpa em torno de $12 \mathrm{~kg} \cdot \mathrm{cm}^{-2}$ (Alves et al., 2002). A acidez total titulável depende da preferência do mercado a ser alcançado.

Frutos fisiologicamente maduros de diversas espécies e cultivares têm sido submetidos a tratamentos com etileno ou seus análogos, tanto em nível experimental como comercial, visando acelerar e uniformizar seu amadurecimento e, ou melhorar seu padrão de qualidade. Em ambos os casos, verifica-se que esse tratamento proporciona considerável redução do período entre a colheita e o completo amadurecimento dos frutos.

A maioria das informações na literatura relata a aplicação de etileno por imersão dos frutos em solução de ethephon (ácido 2-cloroetilfosfônico). Esse tipo de tratamento tem resultado em aceleração do processo de amadurecimento e melhoria da coloração externa de mangas 'Alphonso' e de diversas outras cultivares indianas (LAKSHMINARAYANA et al., 1975).

Considerando a escassez de informações acerca das mudanças bioquímicas e fisiológicas associadas ao amadurecimento de manga após aplicação exógena de etileno, buscou-se avaliar neste trabalho o efeito da aplicação de ethephon sobre características consideradas determinantes na conservação pós-colheita e associadas a atributos de qualidade de mangas cv. Tommy Atkins e cv. Ubá.

\section{MATERIAL E MÉTODOS}

Frutos de mangueiras (Mangifera indica L.) cv. Ubá e cv. Tommy Atkins foram colhidos, em dezembro de 2002, de plantas com 29 anos de idade, pertencentes à coleção de variedades do Pomar Experimental da Universidade Federal de Viçosa $\left(21^{\circ}\right.$ $05^{\prime}$ de latitude Sul, $42^{\circ} 48^{\prime}$ de longitude Oeste e 305 $\mathrm{m}$ de altitude), localizado no município de Visconde do Rio Branco, Minas Gerais.

Foram colhidos frutos com ombros cheios, firmes e com a casca verde. Procurou-se colhê-los ao acaso e de forma eqüitativa nos quatro quadrantes da copa das plantas. Além disso, os frutos foram submetidos a uma seleção prévia no campo, onde se buscou padronizá-los com relação à massa e ao tamanho, além de se evitarem aqueles com sintomas de antracnose, cochonilha, queimados pelo escorrimento de látex e, ou, deformados. Os frutos colhidos foram lavados com água corrente e colocados para secar à sombra.
A amostra total dos frutos foi dividida em duas partes iguais. Metade dos frutos foi imerso em água, e metade, em solução de threl $^{\circledR}\left(240\right.$ g.L ${ }^{-1}$ de ácido 2-cloroetilfosfônico), em concentração de 1.000 $\mathrm{mg} . \mathrm{L}^{-1}$ de ethephon, por 3 minutos. A concentração se refere á mais utilizada em trabalhos anteriores envolvendo o uso de ethephon em mangas (BARMORE, 1974; Bhova et al., 1978; Fuchs et al., 1975; LAKSHMINARAYANA et al., 1975).

No fim desse procedimento, os frutos foram colocados para secar à sombra e mantidos a $26,1 \pm$ $1,8^{\circ} \mathrm{C}$ durante todo o período pós-colheita avaliado.

Do total de 50 frutos colhidos de cada variedade, 10 frutos, com e sem aplicação de ethephon, destinaram-se às seguintes avaliações nãodestrutivas: perda de massa fresca, obtida pela pesagem individual dos frutos em balança digital, atribuindo-se valor $0 \%$ às primeiras medições de massa dos frutos e calculando-se as demais em relação às pesagens anteriores; e índice de coloração da casca (ICC), avaliada visualmente mediante escala subjetiva de notas de cores, diferenciada em função da variedade, em que 1 - totalmente verde; 2 - mais verde que vermelha; 3 - iguais proporções de verde e vermelha; 4 - mais vermelha que verde e 5 - totalmente vermelha, no caso das mangas Tommy Atkins; 1 totalmente verde; 2 - mais verde que amarela; 3 - iguais proporções de verde e amarela; 4 - mais amarela que verde e 5 - totalmente amarela, no caso de mangas Ubá. Em ambos os casos relativos à avaliação da cor da casca, assim como na coloração da polpa e na determinação do índice de degradação de amido, foram utilizados cinco avaliadores previamente treinados.

Nos 30 frutos restantes, as características destrutivas avaliadas foram: firmeza da polpa (F), por meio de um penetrômetro Mc Cormick FT 327, ponteira de $8,0 \mathrm{~mm}$ de diâmetro, em duas posições opostas na região equatorial dos frutos; acidez total titulável (ATT), expressa em teor de ácido cítrico e determinada por titulometria, conforme AOAC (1992); teor de sólidos solúveis (SS), utilizando-se refratômetro manual (ATAGO N1) e resultados expressos em ${ }^{\circ}$ Brix; índice de coloração da polpa (ICP), avaliada visualmente mediante escala subjetiva de notas de cores, sendo $1=$ totalmente branca; 2 = branco-amarelada; 3 = amarela, 4 = amareloalaranjada e 5 = totalmente laranja; índice de degradação de amido (IDA), conforme descrito por FAN et al. (1995), sendo utilizada a escala visual modificada por BROOKFIELD et al. (1997). Nesta escala, 1 = tecido da polpa totalmente escurecido; 2 = clareamento inferior a $10 \%$ no centro da polpa; 3 = clareamento no centro da polpa entre $10 \%$ e $25 \%$; 4 = clareamento entre $25 \%$ e $50 \% ; 5=$ clareamento entre $50 \%$ e $75 \%$ e $6=$ clareamento superior a 75\%. A relação SS/ATT foi calculada pela divisão entre os valores obtidos dessas duas variáveis. 
Para cada uma das duas variedades utilizadas foi desenvolvido um experimento no delineamento inteiramente casualizado, em esquema de parcelas subdivididas com três repetições e um fruto na unidade experimental. A parcela foi constituída pelos tratamentos com e sem aplicação de ethephon e as subparcelas, pelas cinco épocas de avaliação após a colheita (no dia da colheita e aos 3, 6, 9 e 12 dias após a colheita).

Os resultados foram submetidos à análise de variância pelo teste $\mathrm{F}$, ao nível de $5 \%$ de significância. Os efeitos dos períodos de armazenamento foram avaliados por meio de análise de regressão, a $1 \%$ e $5 \%$ de probabilidade pelo teste $t$.

\section{RESULTADOS E DISCUSSÃO}

A evolução do amadurecimento dos frutos, com base na mudança visual da coloração da casca (ICC), mostrou um incremento com tendência linear $(\mathrm{P}<0,01)$ na fase pós-colheita até o $12 .{ }^{\circ}$ dia, nas duas variedades estudadas, com e sem a aplicação de ethephon. Em um primeiro momento, nos frutos recémcolhidos da variedade Tommy Atkins, o índice de coloração da casca estava em torno de 2 , enquanto este índice era de 1 nos frutos da manga cv. Ubá. No 12. ${ }^{\circ}$ dia após a colheita, os frutos tratados com etileno de ambas as variedades atingiram o índice 5 (fundo da casca totalmente vermelho em mangas cv. Tommy Atkins e, totalmente amarelo, na cv. Ubá), ao passo que os não-tratados alcançaram índice 4 (fundo da casca mais vermelho que verde nos frutos $\mathrm{cv}$. Tommy Atkins e, mais amarelo que verde nos da cv. Ubá). Fuchs et al. (1975) relatam que, em frutos maduros das variedades Haden, Maya e Mabruka, o completo amarelecimento foi atingido entre 7 e 8 dias nos frutos tratados com etileno, enquanto para os não-tratados foram necessários 10 dias.

A intensificação na evolução da cor da casca nos frutos tratados com ethephon pode ser atribuída à sua ação em promover a autocatálise da síntese de etileno, ou à liberação de etileno diretamente nos tecidos, essencial ao processo de amadurecimento de frutos climatéricos (OetiKer e YANG, 1995). Em frutos cítricos, que não possuem mecanismo bem definido de amadurecimento, sendo denominados de nãoclimatéricos, o etileno na forma de ethephon é utilizado comumente no desverdecimento, por estimular a degradação de clorofila e ativar a síntese de carotenóides (WATADA, 1986).

Em mangas, a aplicação de ethephon póscolheita resultou em uma técnica muito útil para desencadear esses processos, contribuindo para antecipar a obtenção de frutos com coloração de casca característica de cada variedade, importante atributo de qualidade por condicionar boa aparência ao produto, influenciando diretamente a preferência do consumidor e seu valor de mercado. Tais efeitos podem ser benéficos como, por exemplo, para centrais de distribuição e indústrias de processamento, haja vista a necessidade, muitas vezes, de uniformizar e, ou acelerar o amadurecimento dos frutos, disponibilizando-os em tempo hábil conforme o período de demanda do mercado comprador. Assim, apesar de o Ethrel ${ }^{\circledR}$, produto comercial que possui o ethephon (ácido 2-cloroetilfosfônico) como princípio ativo, não apresentar registro no Brasil para aplicação comercial pós-colheita, o mesmo pode ser promissor para utilização em produtos vegetais comestíveis com a finalidade de induzir o amadurecimento.

Observou-se que as alterações na coloração da polpa (ICP) da manga seguiram também uma tendência linear com o avanço do amadurecimento ( $P$ $<0,01)$, passando de amarelada para amareloalaranjada, no caso da manga cv. Tommy Atkins, e de branco-amarelada para totalmente alaranjada, em frutos da variedade Ubá. A aplicação de ethephon, semelhante ao ocorrido na casca, promoveu uma intensificação na coloração da polpa das mangas cv. Tommy Atkins e cv. Ubá em comparação aos frutos que não foram tratados com o produto. No entanto, esse incremento não foi suficiente para que os frutos da variedade Tommy Atkins alcançassem o índice 5, correspondente à coloração totalmente laranja da polpa.

Medicotic et al. (1987) relatam que o amolecimento da polpa e o desenvolvimento da cor da casca podem ser obtidos com menores concentrações do gás acetileno, enquanto maiores concentrações são requeridas para o desenvolvimento da coloração da polpa. Considerando também a contribuição do etileno endógeno nos tecidos para o início de uma resposta fisiológica ao amadurecimento, provavelmente, no estádio em que os frutos da manga cv. Tommy Atkins foram colhidos, o teor de etileno na polpa e, ou a concentração de ethephon aplicado não tenham sido suficientes para o desenvolvimento pleno da cor da polpa durante o período de armazenamento analisado. É possível também que as condições do ambiente de armazenamento dos frutos tenham interferido negativamente na biossíntese de pigmentos no decorrer do processo de amadurecimento, uma vez que Fuchs et al. (1975) verificaram menor incremento na cor da polpa em frutos armazenados sob elevadas temperaturas.

ABDi et al. (1998) ressaltaram que as mudanças na cor não são necessariamente dependentes de etileno e que a dependência estaria 
associada ao tipo de pigmento, ao tecido onde é sintetizado e à espécie vegetal ou cultivar utilizada. Assim, tratamentos que afetam o metabolismo do etileno podem ter respostas diferentes quanto às modificações na cor durante o amadurecimento.

No 12. ${ }^{\circ}$ dia após a colheita, em frutos da variedade Tommy Atkins submetidos à aplicação de ethephon, o índice de coloração da polpa $(4,4)$ foi inferior àquele verificado nos frutos tratados da variedade Ubá $(4,9)$, indicando, para essa característica, ser a manga $\mathrm{cv}$. Ubá mais sensível à aplicação exógena de etileno.

A perda de massa fresca (PM) foi ligeiramente mais acelerada nos frutos que foram tratados com ethephon em relação aos não-tratados (Figura 1), como também observado em outras espécies submetidas a tratamento com etileno em aplicação pós-colheita (BAlbino, 1997; CAstro et al., 1991). Tratamentos de mangas cv. Tommy Atkins com e sem aplicação de ethephon mantiveram as perdas de massa inferiores a $7 \%$ até o $6 .^{\circ}$ dia de armazenamento; em frutos da mangueira $\mathrm{cv}$. Ubá, as perdas ficaram em torno de $10 \%-12 \%$ considerando o mesmo período e em torno de $20 \%$ no 12 . $^{\circ}$ dia após a colheita. Ao final do período de armazenamento, os níveis foram elevados, o que representaria perdas consideráveis no volume comercializado, uma vez que se utiliza a massa como referência nas operações de venda.

Segundo MAIA et al. (1986), um fruto perde água mais rapidamente em temperaturas elevadas do que em temperaturas mais baixas, mesmo em condições similares de umidade relativa do ar. A maior perda de massa fresca nos frutos tratados poderia ser atribuída ao efeito do etileno que, depois de liberado nos tecidos do fruto, teria alterado a temperatura interna em virtude do aumento da atividade respiratória.

Em frutos da variedade Ubá, submetidos ou não à aplicação de ethephon, em todo o período de armazenamento, houve perda de massa duas vezes maior que a verificada nos frutos da manga cv. Tommy Atkins. Provavelmente, este processo pode ser atribuído à maior sensibilidade da variedade Ubá à exposição ao etileno e à sua biossíntese ou mesmo ao fato de os frutos da cv. Ubá terem sido colhidos em estádio de maturação anterior quando comparados àquele das mangas cv. Tommy Atkins e, consequentemente, com maior sensibilidade à perda de água por transpiração, o que pode ser constatado pelos valores médios observados logo após a colheita referente à coloração da casca e da polpa e da acidez total dos frutos das variedades Ubá $(0,8 ; 2,0$ e 2,7 respectivamente) e Tommy Atkins $(2,0 ; 2,6$ e 0,4 respectivamente).

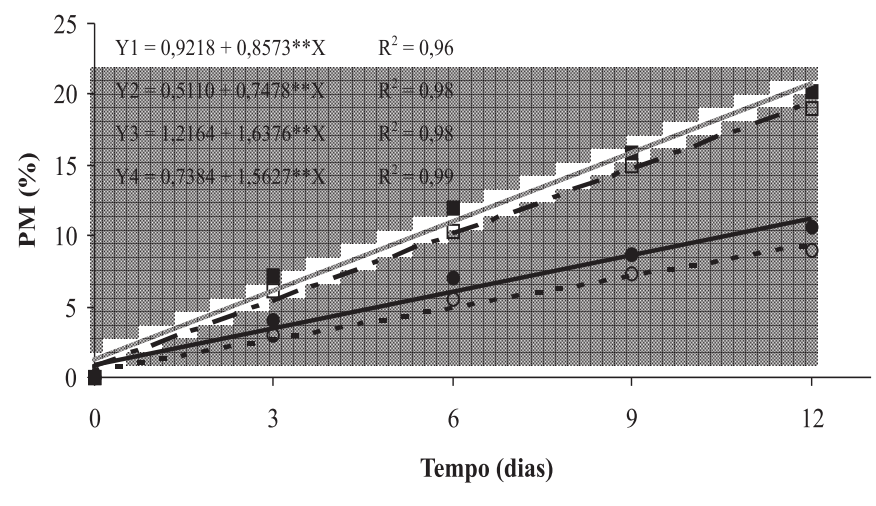

- TA COM ET (Y1) O TA SEM ET (Y2) — UB COM ET (Y3) U UB SEM ET (Y4)

Figura 1. Perda de massa fresca $(P M)$ em mangas $c v$. Tommy Atkins (TA) e cv. Ubá (UB) durante a fase póscolheita, em função da aplicação de ethephon (ET). ${ }^{*} \mathrm{P}<0,05 \mathrm{e}$ ** $\mathrm{P}<0,01$.

Uma das mais flagrantes modificações durante o amadurecimento de frutos climatéricos que contenham reservas de amido em sua constituição celular é a hidrólise deste carboidrato, culminando com o acúmulo de açúcares e o adoçamento da polpa. A redução do conteúdo de amido nos frutos ao longo do amadurecimento ocorre concomitantemente ao aumento nos teores de açúcares totais, açúcares não redutores e sólidos solúveis totais, demonstrando crescente conversão de amido em açúcares simples. Nesse processo, a enzima amilase é uma das principais responsáveis pela hidrólise do amido do fruto em oligossacarídeos (WATADA, 1986). O índice de degradação de amido (IDA) tem sido usado como ferramenta para estudar o desenvolvimento de algumas cultivares de maçãs durante o seu amadurecimento (BROOKFIELD et al., 1997; FAN et al., 1995). A determinação desse índice se baseia na realização do teste iodo-amido, a partir da reação do amido acumulado nas células da polpa dos frutos com uma solução de iodo-KI, produzindo uma coloração escurecida (FAN et al., 1995). Segundo RochA et al. (2001), o índice de degradação de amido mostrou forte correlação com mudanças ocorridas em outros índices durante o amadurecimento da manga cv. Tommy Atkins, podendo ser utilizado como alternativa para estimar a maturação dos frutos.

Assim, a utilização desse indicador revelou que o tecido da polpa dos frutos de todos os tratamentos estava totalmente escurecido (IDA em torno de 1), ou seja, com a área exposta da polpa totalmente tingida com a solução de iodo. Esse processo ocorreu concomitantemente ao estádio de cor verde da casca e esbranquiçada da polpa. 
Após o tratamento com ethephon, no $3 .^{\circ}$ dia de armazenamento, o IDA evoluiu para um clareamento da polpa entre $10 \%$ e $50 \%$ nos frutos de ambas as variedades, ou seja, IDA entre 3 e 4 , enquanto nos frutos não-tratados o índice manteve-se em torno de 2. Com ethephon, o aumento do IDA seguiu tendência de aumento linear até o $6 .^{\circ}$ dia após a colheita; a partir daí, os valores foram descritos como estáveis. Foram necessários três e seis dias para que os frutos dos tratamentos-controle alcançassem os valores obtidos no $6 .^{\circ}$ dia de armazenamento dos frutos com aplicação de ethephon das variedades Tommy Atkins e Ubá respectivamente. No $12 .^{\circ}$ dia após a colheita, tanto os frutos do tratamento-controle quanto aqueles tratados atingiram o nível máximo de degradação do amido acumulado (IDA igual a 5), ou seja, a menor área da polpa do fruto tingida pela solução de iodo, com exceção das mangas cv. Ubá submetidas à aplicação de ethephon, nas quais foi verificado este patamar já no $9 .^{\circ}$ dia de armazenamento. No entanto, pôde-se constatar aumento no índice de degradação de amido dos frutos-controle da variedade Ubá, alcançando clareamento entre $50 \%$ e $75 \%$, semelhante ao verificado nos frutos tratados.

Houve intensa perda de firmeza da polpa ao longo do período de armazenamento (Figura 2), apesar de esta característica ter-se mantido praticamente constante até o sexto dia após a colheita em frutos do tratamento-controle da variedade Tommy Atkins, concomitantemente à obtenção de frutos com cor de casca índice 3. A partir daí, acompanhando o avanço do amarelecimento da casca, houve queda brusca na firmeza da polpa até que, no $12 .^{\circ}$ dia após a colheita, na polpa dos frutos, não houve resistência à pressão exercida pela ponteira do penetrômetro devido à desidratação dos frutos, não sendo mais possível a leitura direta no aparelho. Por outro lado, em frutos da mesma variedade tratados com ethephon, houve declínio mais acelerado na firmeza da polpa, não sendo possível a realização de leitura no aparelho já no sexto dia após a colheita.

Em relação à manga cv. Ubá, a sensibilidade da polpa ao amolecimento foi mais acentuada, sendo possível, nos frutos tratados, apenas a realização de uma única leitura, no dia da colheita, pois foi verificada redução drástica logo no primeiro dia após o tratamento. A firmeza da polpa dos frutos nãotratados da manga cv. Ubá, diferentemente do observado para a variedade Tommy Atkins, foi acentuadamente reduzida já nos primeiros dias após a colheita, não sendo possível fazer leitura no aparelho a partir do $9 .^{\circ}$ dia. Este fato pode estar associado ao efeito do etileno em aumentar a atividade de enzimas hidrolíticas que promovem intensa solubilização das pectinas constituintes da parede celular, resultando em rápida perda de firmeza (Watada, 1986). Assim, concordando com Medlicott et al. (1987), entre as características avaliadas, a firmeza da polpa da manga foi a mais afetada pelo tratamento com ethephon, especialmente em frutos da mangueira cv. Ubá. Haja vista que a textura constitui uma das características determinantes para a sua comercialização, a aplicação de ethephon foi prejudicial, principalmente para mangas da variedade Ubá, pois reduziu a vida útil dos frutos em virtude do total amolecimento da polpa, verificado pelo menos três dias após a colheita.

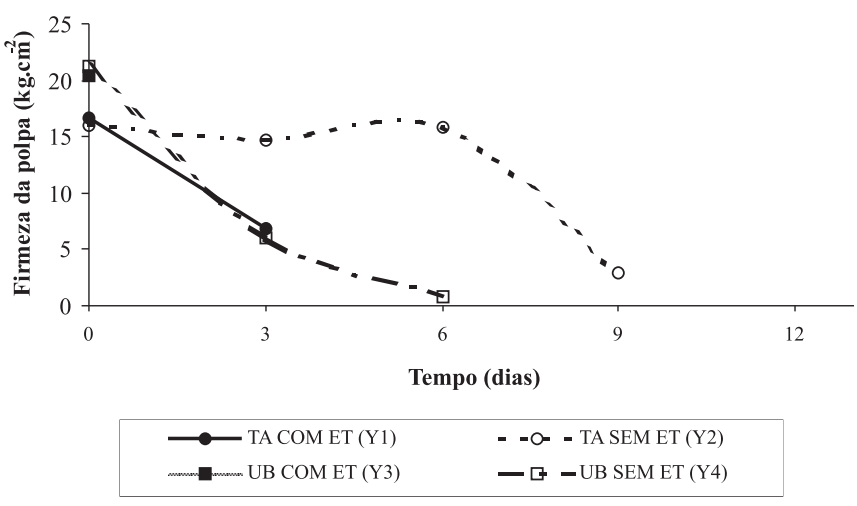

Figura 2. Valores médios de firmeza da polpa de mangas cv. Tommy Atkins e cv. Ubá durante a fase pós-colheita, em função da aplicação de ethephon (ET).

Tanto nos frutos tratados com ethephon como naqueles não-tratados, a falta de resistência da polpa à penetração, correspondente ao total amolecimento, não ocorreu concomitantemente ao completo desenvolvimento da coloração da casca dos frutos. Este fato parece indicar ser a redução na firmeza da polpa uma característica biológica mais sensível ao etileno do que a síntese de carotenóides e a degradação de clorofila na casca e, também, os eventos ocorrem separadamente.

As mudanças nos valores observados de acidez total titulável (ATT) em frutos tratados revelam diferenças na resposta à aplicação pós-colheita de ethephon tanto em mangas cv. Tommy Atkins quanto na variedade Ubá $(P<0,05)$. Entretanto, o acúmulo atípico de ATT verificado nos primeiros dias de armazenamento dos frutos do tratamento-controle de ambas as variedades pode ser decorrente da variabilidade natural da espécie durante a fase de maturação dos frutos. Esse fato dificultou a caracterização mais precisa dessa variável, tendo em vista a tendência de diminuição da acidez total titulável com o avanço do amadurecimento dos frutos 
pela utilização dos ácidos orgânicos como substrato para a respiração (CHITARRA e CHITARRA, 1990). Somente a partir do $3 .^{\circ}$ e $6 .^{\circ}$ dias após a colheita de mangas cv. Ubá e cv. Tommy Atkins respectivamente, é que ocorreu redução no teor de ATT até o fim do período de armazenamento $(2,21 \%$ e $0,71 \%$ respectivamente).

A aplicação de ethephon em mangas de ambas as variedades resultou em uma queda acentuada nos valores de ATT durante todo o período de armazenamento, principalmente em frutos da cv. Ubá, haja vista seus maiores níveis de acidez verificados logo após a colheita $(2,67 \%)$, quando comparados à variedade Tommy Atkins (0,65\%), disponibilizando maior quantidade de ácidos orgânicos para serem convertidos em açúcares solúveis ao longo do processo de amadurecimento dos frutos.

De maneira geral, houve acréscimo $(\mathrm{P}<0,05)$ no teor de sólidos solúveis (SS) durante a fase póscolheita, assim como se observa no decorrer do amadurecimento da maioria dos frutos, estando os valores compreendidos entre 6 e $12^{\circ}$ Brix (Figura 3).

No $12 .^{\circ}$ dia de armazenamento, o maior teor de açúcar foi verificado em mangas cv. Tommy Atkins tratadas com ethephon. No entanto, verificou-se que, para ambas as variedades, a aplicação do ethephon não contribuiu significativamente para acelerar o incremento no conteúdo de SS ao longo do período de armazenamento, em comparação com os frutos nãotratados. Esse aumento no teor de SS ocorrido no decorrer do armazenamento, decorrente do tratamento com ethephon, deve-se ao acúmulo de açúcares verificado durante o amadurecimento de frutos climatéricos que contenham reservas de amido, como resultado da degradação deste carboidrato e, possivelmente, da quebra parcial de pectinas, celulose e outros polissacarídeos (CHITARRA e CHITARRA, 1990). Esses mesmos autores relatam a existência de correlação positiva entre a perda de massa e a concentração de sólidos solúveis em frutos climatéricos. Provavelmente, nesse caso, a proximidade dos valores de SS obtidos nos frutos tratados com ethephon e naqueles do tratamentocontrole se deva à semelhança observada entre os valores de perda de massa observados nos frutos com e sem aplicação de ethephon.

A relação sólidos solúveis / acidez total titulável (SS/ATT), juntamente com o conteúdo de sólidos solúveis são variáveis que influenciam na qualidade organoléptica da manga. No decorrer do período de armazenamento, a relação SS/ATT não manteve os valores iniciais observados no momento da colheita (Figura 4). Em função da elevação do conteúdo de SS e da redução nos níveis de acidez total titulável (ATT), verificou-se aumento mais acentuado
$(\mathrm{P}<0,05)$ na relação SS/ATT das mangas submetidas à aplicação de ethephon ao longo do armazenamento, sugerindo que o uso deste produto em pós-colheita proporcionou maior atividade metabólica dos frutos.

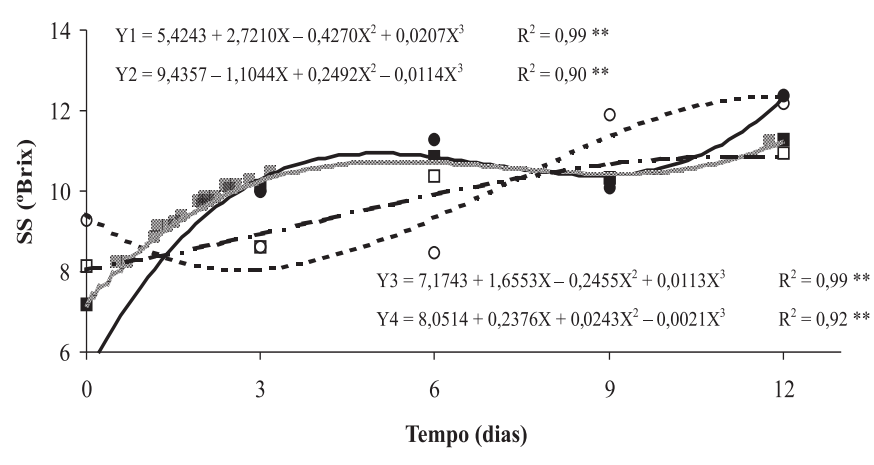

- TA COM ET (Y1) o TA SEM ET (Y2) a UB COM ET(Y3) U UB SEM ET (Y4)

Figura 3. Teor de sólidos solúveis (SS) de mangas cv. Tommy Atkins e cv. Ubá durante a fase pós-colheita, em função da aplicação de ethephon (ET). * $\mathrm{P}<0,05 \mathrm{e}{ }^{* *} \mathrm{P}<0,01$.

Exceto no dia da colheita, os maiores valores foram observados nos frutos da variedade Tommy Atkins submetidos à aplicação de ethephon. O acréscimo da relação SS/ATT para os frutos dessa variedade foi mais acentuado que aqueles do tratamento controle, em decorrência dos menores teores de acidez total titulável observados em todo o período de armazenamento, com exceção do intervalo entre o sexto e o nono dia após a colheita. A mesma tendência foi verificada em mangas cv. Ubá, em que a maior relação SS/ATT deveu-se à redução da ATT, ligeiramente inferior nos frutos sem aplicação de ethephon quando comparados aos frutos tratados. Nessa variedade, as maiores diferenças nos valores da relação SS/ATT foram observadas a partir do $6 .^{\circ}$ dia de armazenamento.

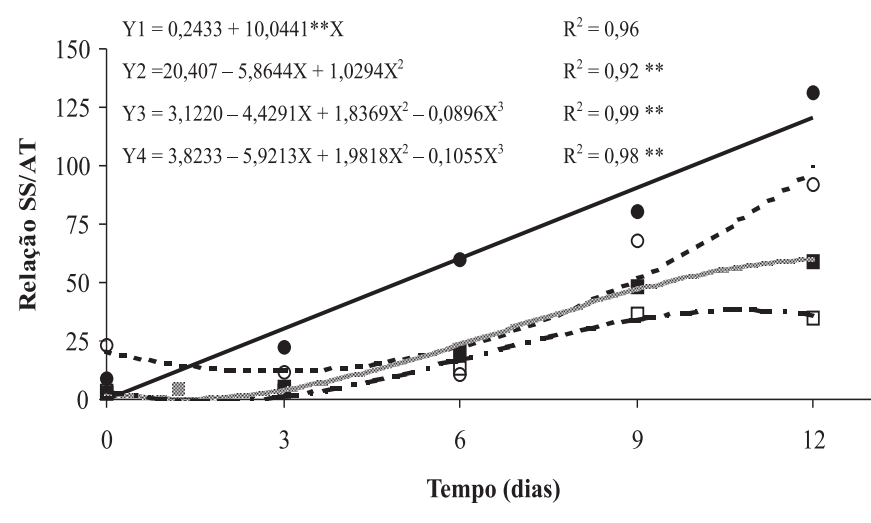

- TA COM ET (Y1) O TA SEM ET (Y2) —UB COM ET (Y3) a UB SEM ET (Y4)

Figura 4. Relação SS/AT da polpa de mangas cv. Tommy Atkins e cv. Ubá durante a fase pós-colheita, em função da aplicação de ethephon (ET). * $\mathrm{P}<0,05 \mathrm{e}$ ** $\mathrm{P}<0,01$. 


\section{CONCLUSÕES}

1. A aplicação pós-colheita de ethephon foi eficiente em acelerar os processos fisiológicos associados ao amadurecimento das mangas $\mathrm{cv}$. Tommy Atkins e cv. Ubá e em contribuir para a obtenção de frutos com características desejáveis em um menor período de armazenamento sob condição ambiente.

2. A aplicação de ethephon interfere na coloração da casca e da polpa, na perda de massa fresca, na firmeza da polpa, no conteúdo de sólidos solúveis, na acidez total titulável, no índice de degradação de amido e na evolução da relação SS/ ATT durante o armazenamento. Entretanto, considerando a importância da firmeza da polpa na qualidade dos frutos comercializados in natura, a aplicação de ethephon foi prejudicial, principalmente para mangas da variedade Ubá, pois reduziu a vida útil dos frutos devido ao seu total amolecimento verificado pelo menos três dias após a colheita.

3. Apesar de os resultados justificarem a possível recomendação para manga, a indicação da aplicação do produto em nível comercial depende de melhor compreensão da técnica no que se refere ao ajuste de doses, em função da cultivar e do estádio de maturação dos frutos, e à sua interferência no metabolismo pós-colheita do fruto sob diferentes condições e procedimentos de aplicação.

\section{REFERÊNCIAS}

ABDI, N.; McGLASSON, W.B.; HOLFORD, P.; WILLIAMS, M.; MIZRAHI, Y. Responses of climateric and suppressedclimateric plums to treatment with propylene and 1methylcyclopropene. Postharvest Biology and Technology, Amsterdam, v.14, n.1, p.29-39, 1998.

ABELES, F.B.; MORGAN, P.W.; SALTVEIT, M.E. Ethylene in plant biology. 2.ed. San Diego: Academic Press, 1997. 414p.

ALMEIDA, C.O.; SOUZA, J.S.; MENDES, L.N.; PEREIRA, R.J. Tendências do mercado internacional de manga. Revista Econômica do Nordeste, Fortaleza, v.32, n.1, p.112-120, 2001.

ALVES, R.E.; FILGUEIRAS, H.A.C.; MENEZES, J.B.; ASSIS, J.S.; LIMA, M.A.C.; AMORIM, T.B.F.; MARTINS, A.G. Colheita e pós-colheita. In: GENÚ, P.J.C.; PINTO, A.C.Q. Manga: Produção. Brasília: Embrapa Informação Tecnológica, 2002, p.381-406.

AOAC-ASSOCIATIONOFOFFICIAL ANALYTICALCHEMISTS. Official methods of analysis. 11.ed. Washington, 1992. 1115p.

BALBINO, J.M.S. Efeitos de hidrotermia, refrigeração e ethephon na qualidade pós-colheita do mamão (Carica papaya L.). 1997. 104p. Tese (Doutorado em Fisiologia Vegetal) Universidade Federal de Viçosa.
BARMORE, C.R. Ripening of mangoes with ethylene and ethephon. Proceedings of Florida State Horticultural Society, St. Petersburg, v.87, p.331-334, 1974.

BERNIZ, P.J. Avaliação industrial de variedades de manga (Mangifera indica L.) para elaboração de néctar. 1984. 57p. Dissertação (Mestrado em Tecnologia de Alimentos) Universidade Federal de Viçosa.

BHOVA, H.P.;PATEL, J.C.; AMIN, H.D. Effect of Ethrel on ripening of some varieties of mango (Mangifera indica L.) fruits. Indian Journal Agricultural Research, New Delhi, v.12, p.263-265, 1978.

BROOKFIELD, P.; MURPAY, P.; HARKER, R.; MACRAE, E. Starch degradation and starch pattern indices: interpretation and relationship to maturity. Postharvest Biology and Technology, Amsterdam, v.11, p.23-30, 1997.

CASTRO, J.V.; FERREIRA, V.L.P.; YOTSUYANAGI, K. Aplicação pós-colheita de etileno e de ethrel no desverdecimento de tangor Murcote. Revista Brasileira de Fruticultura, Cruz das Almas, v.13, n.1, p.237-242, 1991.

CHITARRA, M.I.F; CHITARRA, A.B. Pós-colheita de frutos e hortaliças: fisiologia e manuseio. Lavras: ESAL;FAEPE, 1990.320p.

FAN, X.; MATTHEIS, J.P.; PATTERSON, M.E.; FELLMAN, J.K. Changes in amylose and total starch content in 'Fuji' apples during maturation. HortScience, Alexandria, v.30, n.1, p.104105, 1995.

FAO. FOOD AND AGRICULTURE ORGANIZATION. Disponível em: <http:/ / apps.fao.org>. Acesso em 10 fev. 2004.

FUCHS, Y.; ZAUBERMAN, G.; YANKO, U.; HOMSKY, S. Ripening of mango fruits with ethylene. Tropical Science, Whurr, v.17, p.211-216, 1975.

LAKSHMINARAYANA, S.; SHETTY, M.S.; KRISHNAPRASAD, C.A. Accelerated ripening of 'Alphonso' mangoes by the application of Ethrel. Tropical Science, Whurr, v.17, p.95-101, 1975.

MAIA, G.A.; SILVA, M.F.A.; HOLANDA, L.F.F.; MONTEIRO, J.C.S.; ORIÁ, H.F.; FIGUEIREDO, R.W. Estudo da maturação de algumas variedades de manga (Mangifera indica L.). Revista Brasileira de Fruticultura, Cruz das Almas, v.8, p.67-74, 1986.

MEDLICOTT, A.P.; SIGRIST, J.M.M.; REYNOLDS, S.B.; THOMPSON, A.K. Effects of ethylene and acetylene on mango fruit ripening. Annual Applied Biology, Harpenden, v.111, p.439-444, 1987.

OETIKER, J.H.; YANG, S.F. The role of ethylene in fruit ripening. Acta Horticulturae, Wageningen, v.398, p.167-178, 1995.

ROCHA, R.H.C.; MENEZES, J.B.; MORAIS, E.A.; SILVA, G.G.; AMBRÓSIO, M.M.Q.; ALVEZ, M.Z. Uso do índice de degradação de amido na determinação da maturidade da manga 'Tommy Atkins'. Revista Brasileira de Fruticultura, Jaboticabal, v.23, n.2, p.302-305, 2001.

WATADA, A.E. Effects of ethylene on the quality of fruits and vegetables. Food Technology, Chicago, v.40, p.82-85, 1986. 